ISSN 2616-7328 (Online), ISSN 2409-904X (Print)

Kitaêznavčì doslìdžennâ, 2018, No. 1, pp. 36-57

doi: https://doi.org/10.15407/chinesest2018.01.036

UDC 656.615:005.346

\title{
PORT EXPANSION OF CHINA - LESSONS FOR UKRAINE
}

D. Ilnytskyy

Doctor of Economic Sciences, Associate Professor

Department of International Economics

Kyiv National Economic University named after Vadym Hetman,

54/1, Peremogy ave., Kyiv, Ukraine, 03057

e-mail: ilnytskyy@kneu.edu.ua

\section{S. Zinchenko}

PhD, Department of Personnel Management and Labor Economics

Mariupol Institute of the Interregional Academy of Personnel Management,

62, Gromovoy str., Mariupol, Ukraine, 87556

e-mail: fantomac99@gmail.com

The paper investigates the development of domestic and foreign seaports in conditions of growth of global competition, expansion, implementation of aggressive policies and strategies by competitors. Terminal business always, especially now offers a faster and more guaranteed return of funds, greater return on invested capital. Currently, China owns port terminals in 34 countries and plans to purchase port terminals in 8 countries in the next 2-3 years. So China is going to become a leading maritime power, like England in the $19^{\text {th }}$ century.

In the course of the study, scientific and analytical works, strategies for the development of seaports in China and other countries were studied. The methodology of constructing competitive maps of the global port market, systematization of factors and generalization of modern methods for studying the patterns and features of the development of seaports were used.

The analysis of competitive map revealed significant asymmetries in dynamics and size of market shares of countries in the world port market, which is the result of the implementation of unique national, regional and local strategies. On the example of China, we observe the key drivers of their development - the active use of public-private partnerships, scientific, educational and technological factors.

Keywords: transport infrastructure, world port market, competitive map, economic effect, expansion, investments

\section{ПОРТОВАЯ ЭКСПАНСИЯ КИТАЯ - УРОКИ ДЛЯ УКРАИНЫ}

\author{
Д. А. Ильницкий, С. Г. Зинченко
}

\section{1. Введение}

Развитие европейских транспортных коридоров, особенно между Балтийским и Черным морями, странами ЕС и Азии, происходит в обход Украины. Этот факт и низкая региональная конкурентоспособность украинских морских портов обуславливают снижение международных конкурентных позиций

C 2018 D. Ilnytskyy \& S. Zinchenko; Published by the A. Yu. Krymskyi Institute of Oriental Studies, NAS of Ukraine and the Ukrainian Association of Sinologists on behalf of The Chinese Studies. This is an Open Access article distributed under the terms of the Creative Commons Attribution License (https://creativecommons.org/licenses/by-nc-nd/4.0/). 
компаний и экономики страны, негативное влияние на динамику ВВП. Одним из таких вызовов является оглашение планов возрождения Великого шелкового пути из Китая в Европу вне границ Украины. Более того, качество развития логистической инфраструктуры Украины, без которой развитие внутреннего рынка и выход на внешний крайне затруднены, составляет лишь $56 \%$ среднемирового уровня, что соответствует 71-му месту в мире [Readiness... 2018].

Пример развитых стран (США, Франция, Нидерланды и др.) и многих развивающихся стран Азии (Китай, Южная Корея, Вьетнам) демонстрирует необходимость реализации комплексных стратегий и обеспечения целенаправленных инвестиций на развитие морских портов. Очевидно, что особенности экономико-географического положения, природных условий также влияют на условия развития каждого конкретного порта и, соответственно, его рыночные позиции.

Эти и ряд других вызовов не нашли должного разрешения в развитии морских портов Украины. Приведенные аргументы обуславливают необходимость совершенствования стратегии развития морских портов Украины на основе уникального опыта Китая, современной методологической базы, результатов новейших научных и прикладных исследований.

\section{2. Объект исследования и его особенности}

Объект исследования - возможности использования опыта Китая для развития морских портов Украины в условиях усиления глобальной конкуренции, реализации конкурентами агрессивных политик и стратегий.

Анализ состояния морских портов Украины в сравнении с Китаем и другими иностранными конкурентами дает основания говорить об актуальности пересмотра стратегии их развития на основе доступной информации. Чистый финансовый результат функционирования морских портов Украины и динамика грузопотоков последние три года демонстрируют негативную тенденцию (табл. 1). Поэтому в современной ситуации данная отрасль требует вложения инвестиций и внедрения новых технологий, например со стороны Китая, как лидера портовой инфраструктуры.

Среди приоритетов развития экономики Украины национальный интерес (кроме наращивания экспорта товаров с высокой добавленной стоимостью) представляют вопросы диверсификации источников энергоносителей и других ресурсов, что невозможно без развития возможностей их поставки морем. Здесь также необходимы инвестиции и современный опыт Китая.

Таблица 1

Основные финансовые показатели развития морских портов Украины, млн

\begin{tabular}{|l|l|l|l|l|l|l|}
\hline \multicolumn{1}{|c|}{ Показатель } & \multicolumn{1}{|c|}{ Валюта } & \multicolumn{1}{|c|}{2013} & \multicolumn{1}{|c|}{2014} & \multicolumn{1}{|c|}{2015} & 2016 & 2017 \\
\hline \multirow{2}{*}{ Совокупные активы } & грн & 16656 & 17483 & 20639 & 20682 & 21517 \\
\cline { 2 - 7 } & долл. США & 2084,6 & 1109,3 & 860,0 & 760,6 & 766,8 \\
\hline \multirow{2}{*}{$\begin{array}{l}\text { сезавершенные капитальные инве- } \\
\text { стици }\end{array}$} & 3676 & 2817 & 3133 & 3418 & 3944 \\
\cline { 2 - 7 } & долл. США & 460,1 & 178,7 & 130,5 & 125,7 & 140,6 \\
\hline \multirow{2}{*}{ Чистый доход } & грн & 1870 & 4004 & 6810 & 7297 & 7633 \\
\hline \multirow{2}{*}{ Чистый финансовый результат } & долл. США & 234,0 & 254,1 & 283,8 & 268,4 & 272,0 \\
\hline \multirow{2}{*}{ Курс долл. США на конец года } & грн & 647 & 1512 & 3847 & 3854 & 3605 \\
\cline { 2 - 7 } & долл. США & 81,0 & 95,9 & 160,3 & 141,7 & 128,5 \\
\hline
\end{tabular}

Примечание: составлено по данным финансовой отчетности ГП “Администрация морских портов Украины”. 
Морские порты Украины должны готовиться к изменениям в структуре перевозимых грузов и используемых видов топлива, которые под давлением парадигмы устойчивого развития вызваны необходимостью экологизации экономического развития. Большинство исследователей сходятся на том, что из всех вариантов развития более экологичных видов топлива морских перевозок приоритет отдается сжиженному природному газу (СПГ). Массовое использование СПГ поможет уменьшить эмиссию СО на 15-20 \% [Woo-chul 2014]. Одним из серьезных препятствий внедрения СПГ называют недостаток реальных инвестиций, передовых технологий и опыта. В Китае, США и ЕС также соглашаются, что подготовка персонала влияет на обеспечение безопасности, операционной деятельности в сфере массового использования газа как топлива в портах и на морском транспорте [Sayareh 2014].

Итальянские ученые предлагают для оптимизации размещения контейнерных терминалов Украины использовать модели математического программирования [Hanaoka 2011]. При этом следует учитывать не только мировой опыт, но и особенности сети национальных и международных, межконтинентальных транспортных коридоров, основным из которых является Китай - Европа (ЕС).

К недостаткам развития морских портов Украины также следует отнести несформированность системы научно-аналитического обеспечения деятельности, мониторинга локальных и глобальных вызовов, например рыночных, экологических или технологических [Зинченко 2017, 80]. Исходя из опыта крупнейших портов Китая, система мониторинга должна выявлять тенденции и формировать базис для своевременного и эффективного реагирования на изменения рыночной конъюнктуры, экспансии транснациональных компаний. Более того, ценным для Украины является опыт реализации компетентносных моделей развития портовой инфраструктуры [Ільницький, Зинченко 2017].

\section{3. Цель и задачи исследования}

Целью работы является поиск путей повышения эффективности работы морских портов Украины на основе изучения современной методологической базы, состояния развития мирового рынка и передового опыта портов Китая.

Для достижения поставленной цели были поставлены такие задачи:

1) систематизировать факторы развития морских портов;

2) построить конкурентную карту мирового портового рынка и идентифицировать его лидеров и аутсайдеров, в т. ч. позиции Китая и Украины;

3) определить особенности развития морских портов на примере Китая в условиях экспансии транснациональных компаний;

4) обосновать ключевые пути управления конкурентоспособностью для морских портов Украины, которые могут быть заложены в стратегию развития.

\section{4. Анализ существующих решений проблемы}

Решение указанных проблем особенно перспективно в условиях, когда развитие транспортных коридоров из Азии в Европу осуществляется в обход Украины. При этом низкая региональная конкурентоспособность украинских морских портов обуславливает снижение международных конкурентных позиций экономики Украины. Ритмичность работы морских портов дает стабильность в работе других отраслей и прилегающих к ним регионов, что видно на примере развития ведущих портов мира, особенно Китая.

Начиная с 1980 года наиболее активным является период с 2008 года, ког- 
да исследования компонентов конкурентоспособности портов включали наибольшее количество элементов [Galvao 2016]. C 2000 года количество публикаций имеет постоянную тенденцию к увеличению, что обусловлено не только необходимостью принятия решений на основе исследований, но и возрастающим вниманием к портам, как важным узловым, связывающим экономическим агентам (табл. 2).

Методологические основы имеют многие публикации, однако следует выделить актуальность использования современных многокритериальных методов анализа эффективности морских портов [Awad-Núñeza 2014; Libardo, Parolin 2012; Wiśnicki 2016]. Повышение роли науки и образования в обеспечении эффективности деятельности морских портов, как показывает пример Китая, приводит к реализации уникальных корпоративных стратегий, опыт которых может быть перенесен на национальный уровень [Gogas 2017]. Ocoбенно следует выделить работы, которые уделяли основное внимание различным теоретическим и практическим аспектам функционирования портов интеграционным, логистическим, технологическим, региональным, эксплуатационным и экологическим [Зинченко 2017; Container shipping 2017; Esmer 2010; Review... 2017; Sutomo 2012].

Технологии развития морских портов очень разнообразны, и, как правило, публикации рассматривают лишь отдельно взятую из них. Детерминантами их выбора являются специфика перевозимых грузов и особенности экономико-географического положения порта. О них говорят при изучении вопросов эксплуатации и ремонта объектов морских портов [Зинченко 2017; Esmer 2010].

Таблица 2

Динамика количества публикаций на портовую тематику, ед.

\begin{tabular}{|c|c|c|c|c|c|c|}
\hline & \multicolumn{2}{|c|}{ Поисковое слово “роrt” } & \multicolumn{2}{|c|}{$\begin{array}{c}\text { Поисковое слово } \\
\text { "sеaport” }\end{array}$} & \multicolumn{2}{c|}{$\begin{array}{c}\text { Поисковое слово } \\
\text { "рort competition” }\end{array}$} \\
\cline { 2 - 7 } Атрибуты \\
$\begin{array}{c}\text { поиска/ } \\
\text { период }\end{array}$ & $\begin{array}{c}\text { по назва- } \\
\text { нию, ключе- } \\
\text { вым словам } \\
\text { и аннотации }\end{array}$ & $\begin{array}{c}\text { по на- } \\
\text { полям } \\
\text { пванию, } \\
\text { ключевым } \\
\text { словам и } \\
\text { аннотации }\end{array}$ & $\begin{array}{c}\text { по всем } \\
\text { полям } \\
\text { нию, ключе- } \\
\text { вым словам } \\
\text { и аннотации }\end{array}$ & $\begin{array}{c}\text { по всем } \\
\text { полям }\end{array}$ \\
\hline Всего & $\mathbf{2 5 2 2 9}$ & $\mathbf{8 0 5 1 9 3}$ & $\mathbf{4 1 3}$ & $\mathbf{5 8 4 2}$ & $\mathbf{4 5 3}$ & $\mathbf{5 9 0 6 2}$ \\
\hline 2018 & 691 & $\mathbf{9 7}$ & 12 & $\mathbf{1 7 5}$ & 175 & $\mathbf{9 4 0}$ \\
\hline 2017 & 1902 & $\mathbf{2 4 0 9 0}$ & 45 & $\mathbf{4 3 0}$ & 430 & $\mathbf{2 3 8 1}$ \\
\hline 2016 & 1754 & $\mathbf{2 2 1 8 2}$ & 55 & $\mathbf{3 9 9}$ & 399 & $\mathbf{2 1 0 5}$ \\
\hline 2015 & 1704 & $\mathbf{2 1 5 2 8}$ & 42 & $\mathbf{3 5 1}$ & 351 & $\mathbf{1 9 9 3}$ \\
\hline 2014 & 1554 & $\mathbf{2 0 1 4 5}$ & 37 & $\mathbf{3 1 4}$ & 314 & $\mathbf{1 9 0 2}$ \\
\hline 2013 & 1382 & $\mathbf{1 9 9 3 9}$ & 30 & $\mathbf{2 7 8}$ & 278 & $\mathbf{1 8 0 5}$ \\
\hline 2012 & 1220 & $\mathbf{1 8 2 4 1}$ & 26 & $\mathbf{1 9 4}$ & 194 & $\mathbf{1 5 5 4}$ \\
\hline 2011 & 1189 & $\mathbf{1 7 9 2 8}$ & 26 & $\mathbf{1 9 5}$ & 195 & $\mathbf{1 4 7 6}$ \\
\hline 2010 & 1105 & $\mathbf{1 6 4 3 7}$ & 14 & $\mathbf{1 5 3}$ & 153 & $\mathbf{1 3 1 9}$ \\
\hline 2009 & 1050 & $\mathbf{1 6 9 4 2}$ & 11 & $\mathbf{1 8 7}$ & 187 & $\mathbf{1 3 6 5}$ \\
\hline 2008 & 938 & $\mathbf{1 6 7 0 7}$ & 10 & $\mathbf{1 4 5}$ & 145 & $\mathbf{1 4 4 1}$ \\
\hline 2007 & 806 & $\mathbf{1 6 3 9 5}$ & 9 & $\mathbf{1 5 4}$ & 154 & $\mathbf{1 3 4 8}$ \\
\hline 2006 & 773 & $\mathbf{1 5 8 6 9}$ & 14 & $\mathbf{1 4 3}$ & 143 & $\mathbf{1 2 8 0}$ \\
\hline
\end{tabular}




\begin{tabular}{|c|c|c|c|c|c|c|}
\hline 2005 & 711 & $\mathbf{1 4 9 2 9}$ & 6 & $\mathbf{1 0 5}$ & 105 & $\mathbf{1 1 2 8}$ \\
\hline 2004 & 712 & $\mathbf{1 3 6 8 2}$ & 10 & $\mathbf{1 1 5}$ & 115 & $\mathbf{1 0 2 0}$ \\
\hline 2003 & 606 & $\mathbf{1 2 6 6 1}$ & 4 & $\mathbf{8 0}$ & 80 & $\mathbf{1 0 2 6}$ \\
\hline 2002 & 532 & $\mathbf{1 1 1 5 8}$ & 6 & $\mathbf{8 6}$ & 86 & $\mathbf{9 7 8}$ \\
\hline 2001 & 527 & $\mathbf{1 1 3 5 8}$ & 2 & $\mathbf{7 0}$ & 70 & $\mathbf{9 9 0}$ \\
\hline $\begin{array}{c}2000 \text { и } \\
\text { ранее }\end{array}$ & 6072 & $\mathbf{6 1 0 5 7}$ & 54 & $\mathbf{3 3 3}$ & 333 & $\mathbf{3 3 0 1 0}$ \\
\hline
\end{tabular}

Взаимодействие сухих и морских портов проанализировано в работах [Наnaoka 2011; Rudjanakanoknad 2014; Seo 2010]. Новые энергоэффективные виды грузоперевозок рассматриваются преимущественно на примере развитых стран [Sayareh 2014; Woo-chul 2014]. Аналогичный вывод делаем и по результатам рассмотрения экологических аспектов работы морских портов [Libardo, Parolin 2012]. Кроме того, значительное влияние на использование технологий в стратегиях развития морских портов оказывают их размеры, что особенно очевидно для портов Китая [Ambrosino 2014; Bagočius 2013; Ports strategy... 2016].

Различные регионы мировой экономики в разной степени представлены в публикациях, посвященных вопросам развития морских портов. Наиболее часто исследования рассматривают деятельность крупнейших и динамично развивающихся морских портов Европы, Северной Америки, Северной Африки и Юго-Восточной Азии [Gianfranco 2014; Olba 2015; Urbanyi-Popiołek 2016].

Таким образом, результаты обзора публикаций позволяют сделать вывод о том, что проблема повышения эффективности работы морских портов не нова в мировой науке, была исследована в различных аспектах. Однако комплексного обобщения системы факторов и тенденций развития морских портов, идентификации и управления их конкурентными позициями, а также их реализации в форме национальных или корпоративных стратегий не встречалось. Вопрос повышения эффективности работы морских портов и отрасли в целом должен учитывать результаты эволюции научной мысли и практики. Это обуславливает необходимость актуализации теоретической базы, выявления новых закономерностей и особенностей развития морских портов Украины на примере страны, имеющей крупнейшие в мире порты, - Китая.

\section{5. Методы исследований}

Методологическая база развития морских портов представляет собой синтез таких ключевых течений современной науки, как парадигма технологического развития, институционализм, теория мирового рынка, регионализма и международной интеграции, микро- и макроэкономики, концепции устойчивого развития. Наиболее часто субъектами, которые принимают участие в развитии морских портов и потребляют их услуги, называют:

- государство (как регулятор, разработчик политик, потребитель);

- заказчики (торговые и транспортно-логистические компании);

- обслуживающие компании, предоставляющие сопутствующие услуги;

- собственники капитала;

- руководство порта, работники и профсоюзы.

Линейные и нелинейные модели, а также преобразование нелинейных в линейные традиционно используются для исследований закономерностей и особенностей развития транспортной инфраструктуры [Urbanyi-Popiołek 2016]. Сетевые модели и методы определения ключевых показателей эффективности 
наиболее часто используются для сравнения портовых терминалов с точки зрения размера, обрабатывающего оборудования, времени работы, пропускной способности и других признаков. Они являются эффективными для выбора клиентов и экспедиторов конкретного терминала, что представляет маркетинговый интерес из соображений развития цепи поставок, принятия решений пользователями портовых терминалов. Для визуализации результатов исследователи пользуются матрицей парного сравнения показателей, которым присваиваются весовые коэффициенты, что позволяет их ранжировать. Использование теории игр дало возможность выявить ключевые факторы выбора потребителями услуг морского порта, которыми являются размер порта и система стимулирования [Ambrosino 2014].

Логическим продолжением ранжирования является составление различных сбалансированных оценок, индексов (индекс удовлетворенности клиентов, финансовый индекс; индекс кооперативных отношений, индекс нерыночных инструментов [Readiness... 2018]), к которым можно смело добавлять рейтинги. Для измерения активности использования портами инструментов упрощения процедур торговли для роста производства предоставляемых услуг исследователи предлагают использовать расчет индексов. В данном случае компонентами индекса стали такие компоненты, как:

1) портовая инфраструктура;

2) портовый менеджмент;

3) таможенные процедуры;

4) прозрачность внедрения таможенного законодательства.

Морским портам для планирования и прогнозирования потоков грузов необходимо опираться на определенные аналитические модели. Так, развитие технологий и изменение приоритетов социально-экономического развития в направлении экологизации накладывает свой отпечаток на количественные и качественные характеристики портов и терминалов. Например, для определения оптимального количества оборудования для обработки контейнеров часто используется имитационная модель [Клепиков 2016]. Развитие информационных технологий также обуславливает необходимость использования программного обеспечения как в текущей деятельности морского порта, так и для проведения исследований. Современные технологии управления такими сложными системами, как морские порты, опираются на использование информационных и информационно-коммуникационных технологий. Так, программное обеспечение Flow Map, представляющее собой комбинацию карт и блок-схем, которые показывают имитацию пространственного перемещения объектов, может использоваться для идентификации потока товаров, сети трафика и скорости миграции данных, проведения маркетинговых исследований [Wiśnicki 2016].

Стратегические особенности накладывает и вектор специализации перевозимых грузов - экспорт/импорт. Китай, который занимает крупную нишу на мировом рынке, эффективно использует возможности морского транспорта и портовой инфраструктуры, чего не можем сказать об Украине (табл. 3).

Существуют значительные различия в добавленной стоимости, связанной с категориями обрабатываемых грузов. Анализ добавленной стоимости по типам грузов в портах Китая и США показал, что значения могут отличаться до 10 раз: одна тонна обработанного зерна генерирует в среднем 20 долларов, автомобилей - 220 долларов, а контейнерных грузов - 90 долларов [Song 2017]. 
Функционирование и развитие портов необходимо рассматривать с точки зрения их эффективности, что особенно перспективно для разработки стратегий и программ развития, исходя из опыта Китая. Примером может выступать использование многокритериального анализа на основе таких групп критериев:

1) локальная пространственная система;

2) национальная транспортная система;

3) национальная безопасность;

4) эксплуатационные и технические характеристики;

5) типы товаров;

6) портовые услуги;

7) стоимость логистических услуг [Wiśnicki 2016].

Таблица 3

Место основных морских стран в международной торговле в 2016 году, \%

\begin{tabular}{|l|c|c|c|c|}
\hline \multirow{2}{*}{ Страна } & \multicolumn{2}{|c|}{ Доля в мировом объеме } & \multicolumn{2}{c|}{ Доля в ВВП страны } \\
\cline { 2 - 5 } & Экспорт $\downarrow$ & Импорт & Экспорт & Импорт \\
\hline Китай & $\mathbf{1 3 , 1 5}$ & $\mathbf{9 , 7 8}$ & $\mathbf{1 9 , 6}$ & $\mathbf{1 7 , 4}$ \\
\hline США & 9,12 & 13,88 & 11,9 & 14,7 \\
\hline Германия & 8,40 & 6,50 & 46,1 & 38,1 \\
\hline Япония & 4,04 & 3,74 & 16,1 & 15,1 \\
\hline Нидерланды & 3,57 & 3,10 & 82,4 & 71,4 \\
\hline Южная Корея & 3,11 & 2,50 & 42,2 & 35,4 \\
\hline Великобритания & 2,57 & 3,92 & 27,9 & 30,1 \\
\hline Мексика & 2,34 & 2,45 & 38,2 & 40,0 \\
\hline Сингапур & 2,07 & 1,74 & 172,1 & 146,3 \\
\hline Австралия & 1,19 & 1,21 & 18,9 & 21,1 \\
\hline Малайзия & 1,19 & 1,04 & 67,7 & 61,0 \\
\hline Бразилия & 1,16 & 0,88 & 12,5 & 12,1 \\
\hline Россия & 1,77 & 1,18 & 25,7 & 20,6 \\
\hline Индия & 1,65 & 2,21 & 19,2 & 20,6 \\
\hline Украина & $\mathbf{0 , 2 3}$ & $\mathbf{0 , 2 4}$ & $\mathbf{4 9 , 3}$ & $\mathbf{5 5 , 5}$ \\
\hline Египет & 0,16 & 0,34 & 10,3 & 19,7 \\
\hline Среднемировой показатель & - & - & 28,5 & 27,8 \\
\hline
\end{tabular}

Примечание: составлено по [Ilnytskyy 2017; Notteboom 2017].

Для изучения эффективности функционирования портов часто используют методику Promethee, которая особенно важна для оценки производительности [Thomson 2015]. Более того, для оценки эффективности выполняемых функций и ключевых показателей может использоваться бенчмаркинг [Ільницький, Зінченко 2017]. Однако следует отметить, что его использование должно опираться на получение показателей на основе единой методологической базы, что составляет значительную проблему также для большинства известных методик исследования портов. Принятие стратегических решений также должно принимать во внимание результаты $S W O T$-анализа.

Исследователи подтверждают предположения, что для проведения международных сравнений, бенчмаркинга недостаточно статистических данных, полученных на одной методологической основе [Li 2014]. Одним из универсальных показателей следует признать объемы перевалки грузов за 
определенный период (как правило, 1 год и более). В целом основными группами критериев оценивания конкурентоспособности морских портов можно назвать публичные и рыночные коммуникации, информационные технологии, развитие окружающей среды, инженерные средства, круизное и навигационные обеспечение, управленческая эффективность.

\section{6. Результаты исследования}

Среди тенденций развития портовой инфраструктуры особое место занимает увеличение внимания экологическим аспектам, которые в ближайшие десятилетия будут иметь определяющее значение как для самой инфраструктуры, так и для транспорта. Обеспечение устойчивого развития актуализируется не только в развитых странах, но и странах Азии. Исследование экологических аспектов развития портов Китая, Индии, Южной Кореи, Таиланда и других стран выявило, что важнейшим для минимизации негативного влияния на экологию является обеспечение надежного железнодорожного сообщения морского порта с внутренними территориями [Rudjanakanoknad 2014].

Реализация Китаем уникальной стратегии развития портовой инфраструктуры может служить примером для развития отечественных портов. Поэтому позитивно оцениваем тот факт, что в декабре 2017 года Украина и Китай подписали план действий в рамках “Экономического пояса Шелкового пути” и “Морского шелкового пути в XXI ст.", что заметно активизировало сотрудничество двух стран.

Проведенное исследование позволило построить конкурентные карты мирового рынка портовых услуг на основе главного показателя - валового объема перевозок в тоннах (табл. 4), который характеризует все виды грузов. В целом карты демонстрируют наличие динамичных конкурентных условий развития рынка и, соответственно, портовой отрасли. А ведущие позиции занимают те порты и страны (в частности, Китай), которые последние десять лет реализовывали стратегии развития с учетом всех очерченных факторов. Позиции стран соответствуют их месту на мировом рынке (табл. 3), кроме Германии, которая значительную часть товарных потоков транспортирует по суше и активно пользуется возможностями иностранных морских портов.

В совокупности 213 портов, которые анализировались, как в 2010-м, так и в 2015 году обеспечивали $87 \%$ мирового рынка контейнерных перевозок, объемы которых за последние 6 лет выросли на четверть. А по прогнозам McKinsey Global Institute, 50-летний прогноз которого в 1967 году оправдался, объемы контейнерных перевозок до 2067 года могут вырасти от 2,5 до 4,5 раза в зависимости от перспектив развития мировой экономики [Sugawara 2017]. Ожидается, что перевозки настолько будут базироваться на технологиях, что практически станут независимыми от человека, что потребует эффективного использования всех ресурсов и факторов.

Считается, что чем ближе расположены морские порты одной или разных стран, тем более жесткая между ними конкуренция за клиентов и партнеров [Ambrosino 2014]. Однако анализ развития конкуренции на мировом рынке показал, что ее интенсивность неизменно является достаточно высокой. Крупнейшие 10 морских портов (6 из них находятся в КНР) в совокупности контролировали $35,6 \%$ рынка контейнерных перевозок как в 2008, так и в 2015 году, а 50 крупных морских портов - 70,9 и 71,2 \% соответственно. 
壵

\begin{tabular}{|c|c|c|c|c|c|}
\hline \multirow{4}{*}{ 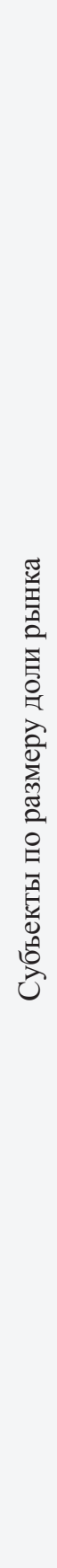 } & 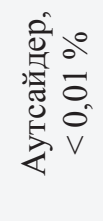 & 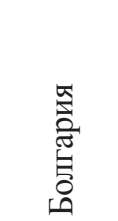 & I & 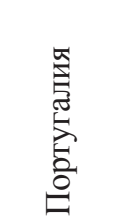 & 1 \\
\hline & 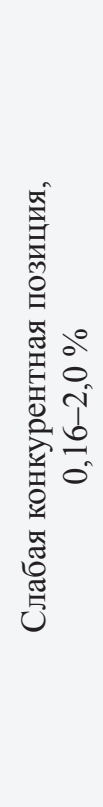 & 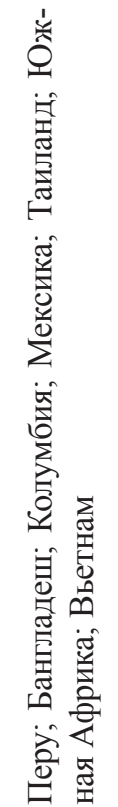 & 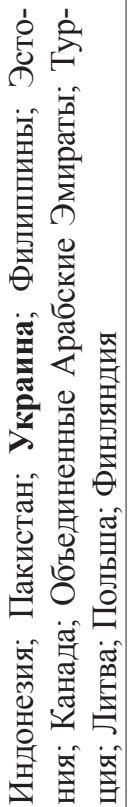 & 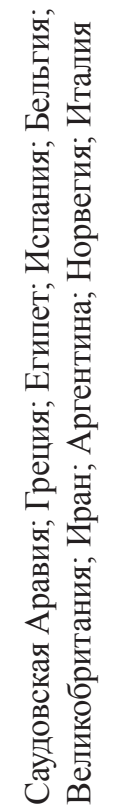 & 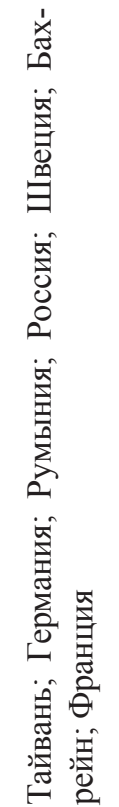 \\
\hline & 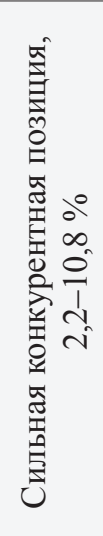 & 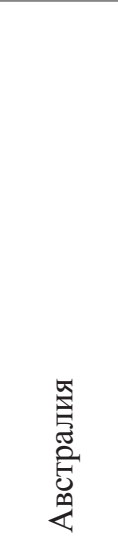 & 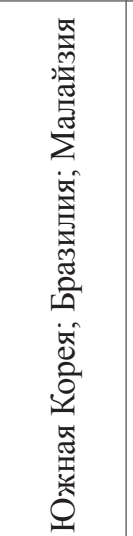 & 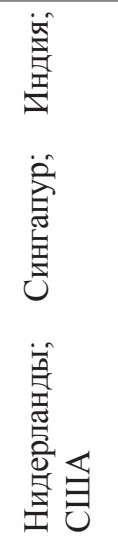 & 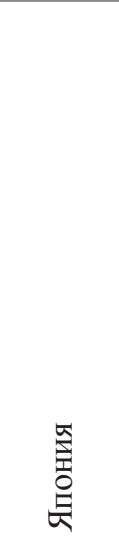 \\
\hline & 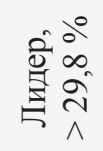 & 1 & 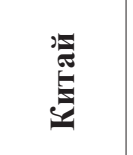 & 1 & 1 \\
\hline & 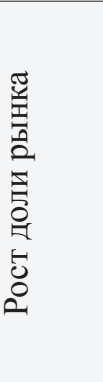 & 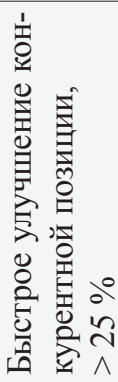 & 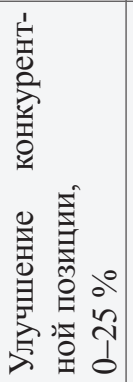 & 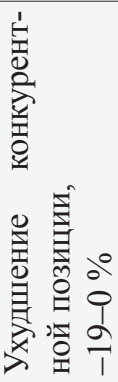 & 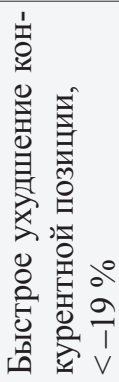 \\
\hline
\end{tabular}


Подобные выводы об интенсивности подтверждаются как для перевозок, которые измеряются в тоннах в отдельных морских портах, так и в масштабах сравнения стран. Хотя основные конкуренты практически не уходят с рынка, однако преимущества получают прежде всего пользователи более качественных портовых услуг, которые влияют на экономическое развитие стран. Подтверждает полученные результаты и анализ индекса лайнерного сообщения. Он дает возможность группировать страны, среди которых ведущими морскими державами можно назвать Китай, Сингапур, Южную Корею, Малайзию, Нидерланды, США, Германию, Бельгию, Великобританию и Испанию [Hamzah 2014]. Эти страны занимают значительную долю мирового рынка, соответственно, 29,8, 3,2, 6, 0, 2,3, 3,4, 10,9, 1,6, 1,5, 1,8 и 1,9 \% (всего - 62,4\%).

Анализ конкурентоспособности портовых городов выявил глобальный тренд смещения глобального распределения сил на мировом рынке. Если в 1972 году около 40 \% мировой деятельности морских портов осуществлялось в Европе, 20 \% - в Северной Америке и 20 \% - в Азии, то к 2009 году ситуация резко изменилась - в Азии произошло более $50 \%$ мировой активности морских портов, в Европе - около $20 \%$ и в Северной Америке - 10 \% [Song 2017]. Данный тренд сформировался на базе реализации морскими портами Азии, прежде всего Китая, агрессивных маркетинговых стратегий развития, тогда как порты в Северной Америке и Европе использовали смешанные комплексные модели роста, которые оказывают значительное влияние на локальную и международную конкурентоспособность портов. Исследователи Южной Кореи и Китая выделяют различные модели взаимодействия портов и городов - морские кластеры, портопромышленное развитие и развитие морских портов, а также комбинации известных моделей [Song 2017].

Портовые мощности позволяют контролировать рынки сбыта. Иностранные порты скупаются для снижения цены собственного товара для конечного потребителя. Т. е. если страна контролирует порт, то сместить ее производителей с внутреннего рынка проблематично. В последние годы национальные стратегии развития морских портов наиболее активно реализуются в Китае (доля мирового рынка выросла с 24,9 \% до 29,8 \%), Южной Корее (6 \%), Австралии (с 4,7 \% до 6,4 \%). Однако позиции других стран ухудшаются - США (с 13,1 \% до 10,9 \%), Франции (с 2,2 \% до 1,6 \%), Германии (с 2,1 \% до 1,6 \%), Канады (1,7 \%), Марокко, Российской Федерации (с 1,8 \% до 1,4%) (табл. 4).

Исследователи [Кузнецов 2015; Gianfranco 2014] предлагают для развития средиземноморского кластера использовать возможности совместной подготовки персонала и обмена сотрудниками. Среди обязательных направлений преодоления трудностей развития морской портовой отрасли Китая в 2014 году названо компетентностное - улучшение обучения и подготовки персонала, а также ускорение научных исследований и технологий.

Китай - крупнейший мировой экспортер и второй по размерам импортер. Для крупнейшего в мире экспортера критически важно контролировать перевалочные мощности, поэтому Китай активно покупает порты по всему миру. Китайская компания Cosco купила за 200 млн евро 51 \% акций испанского портового холдинга Noatum Port Holdings, а недавно сообщила о покупке у датского Maersk $100 \%$ акций контейнерного терминала в порту Зебрюгге (Бельгия). А одним из главных событий минувшего лета в портовой отрасли стала победа китайского консорциума СCCC (China Communications Construction Company) в конкурсе на право строительства нового контейнерного терминала в порту Гамбурга. В Европе Китай контролирует уже $10 \%$ всей 
портовой инфраструктуры для перевалки контейнеров. В мировом масштабе в начале десятилетия это был $1 \%$, а в начале 2017 года $-6,5 \%$, т. е. экспансия сейчас находится в самой активной фазе [Readiness... 2018].

За пределами Европы список китайских портовых приобретений еще более внушителен. К примеру, в конце 2015 года SIPG выиграла контракт на строительство и эксплуатацию порта Хайфа в Израиле, куда планируют инвестировать порядка 2 млрд долларов, сделав этот порт крупнейшим в Израиле с объемом перевалки контейнеров в 1,86 млн TEU в год. Новой точкой роста стала Латинская Америка, где в начале сентября гонконгской компанией CMPort было куплено $90 \%$ акций контейнерного терминала в бразильском порту Паранагуа за 920 млн долл. США (Китай планирует довести его мощность с нынешних 1,5 млн до 2,4 млн TEU всего за два года). Еще одним важным пунктом экспансии оказалась Шри-Ланка, правительство которой одобрило продажу КНР 85 \% акций порта Хамбантот за 1,12 млрд долл. США [Сайт компании... 2017].

Китайские компании Cosco и China Merchants имеют решающее преимущество перед своими, главным образом европейскими, конкурентами: легкий доступ к дешевым деньгам, которые они могут использовать для агрессивной подачи заявок на участие в тендерах на концессию, если говорить о привлекательных объектах по всему миру [Муравский 2018]. Обе компании могут получать займы с низким процентом от государственных банков, а Cosco может даже воспользоваться финансированием OBOR (инициатива "Один пояс, один путь”), предоставленным Банком развития Китая. Доступность дешевых кредитов и мощная дипломатическая поддержка дают китайским операторам терминалов преимущество перед инвесторами-конкурентами и позволяют победить в схватке за портовые активы [Гапочка 2017]. И здесь есть чему поучиться украинским менеджерам портов.

\section{7. Возможности для китайских инвестиций в Украине}

Развитие основных 37 морских портов Китая демонстрирует пример эффективного внедрения стратегии постепенной децентрализации. Об эффективности функционирования морских портов говорит тот факт, что Китай является ведущим мировым экспортером товаров, основную долю которых страна отправляет именно морским транспортом. Портовая отрасль КНР прошла три основных этапа развития:

1) 1949-1984 гг. - интеграция и контроль Министерства коммуникаций;

2) 1985-2001 гг. - совместное управление министерством и местными портовыми администрациями;

3) с 2002 года - управление местными портовыми административными бюро, с большой долей участия частного капитала [Хu 2012].

С 1992 по 2011 года Китай направил 8,5 \% ВВП на инвестиции в инфраструктуру, что значительно превышает показатели США и ЭС (по 2,6 \%), Индии $(3,9 \%)$ и Японии (4,7 \%) [Chen, Matzinger, Woetzel 2013]. Значительная часть этих инвестиций направлялась на развитие портов и связанных с ними объектов транспортной инфраструктуры (дорожной, водной), которые расположены преимущественно на востоке и юге страны. Их реализация возложена на десятки институтов - банков и фондов, агентств и проектов [Chan 2018].

Фактически принцип децентрализации начал активно внедрятся с 2004 года, когда был принят закон о портах, которые должны были становится более 
автономными и коммерчески ориентированными. Китаю удалось привлечь иностранные инвестиции в развитие портовой инфраструктуры, даже несмотря на ограничение иностранной доли в $49 \%$. В процесс развития морских портов активно вовлечены как предприятия, так и местные органы власти. В последние 2 этапа активно использовался инструмент создания свободных (специальных) экономических зон, особенно для развития контейнерных терминалов и привлечения торговых потоков [Notteboom 2017].

Децентрализация морской портовой отрасли Китая сопровождается рядом сопутствующих процессов. Одним из них является целенаправленное участие государственных предприятий КНР в развитии иностранных портов, особенно тех, которые находятся в сфере интересов возрождения шелкового пути. Так, крупнейшая судоходная компания Китая Cosco Рacific в 2016 году в Греции приобрела $51 \%$ акций морского порта Пирей (Piraeus), который рассматривается как один из важнейших транспортных узлов Шелкового пути [Gogas 2016].

Портовые администрации, которые имеют статус государственных предприятий, фактически функционируют и развиваются в условиях рыночных отношений. Это вынуждает их учитывать особенности плановой экономики и использовать маркетинговые подходы для работы с клиентами и привлечения инвестиций. Децентрализация и тренды замедления торговли и экономического развития привели к тому, что в Китае сформировались избыточные портовые мощности, которые, как и в Украине, недоиспользуются на 35 \%, повысилась конкуренция между морскими портами [Sutomo 2012].

Одновременно формируются интегрированные портовые кластеры (сегодня исследователи выделяют в Китае 7 крупных портовых кластеров), в развитие которых вовлекаются внутренние регионы страны через транспортные коридоры и сухие порты. Более того, происходит как привлечение иностранных инвестиций и международных торговых потоков, так и активная интернационализация компаний, связанных с портами, что так необходимо для морских портов Украины.

Китай становится все более важным торговым партнером Украины. На фоне замедления экономик большинства стран власти Китая хотят реализовать масштабный инфраструктурный проект - “Новый шелковый путь”, призванный экономически соединить Азию с Европой. Проект предусматривает создание новой и развитие существующей портовой инфраструктуры, совмещенной с сетью железных дорог. И Украина пока еще может стать стратегической частью данного проекта, так как имеет выгодное географическое положение перспективного транзитного хаба и логистического центра.

Уровень инвестиционной привлекательности Украины для КНР будет увеличиваться по мере решения в стране вопросов обеспечения надежной защиты инвестиций, обеспечения свободного движения капитала. Также для Китая фактором привлекательности Украины является ее аграрный потенциал и ITиндустрия (в основном программное обеспечение). Поэтому Украина может стать одним из главных бенефициаров китайской экономической экспансии.

Китайские компании уже успешно работают в Украине, например китайская компания China harbor engineering company выиграла 2 тендера и успешно провела дноуглубление в порту “Южный”, экономия для Украины составила более 500 млн гривен. Также ожидается, что крупнейший мировой контейнерный портовый оператор Hutchison Ports (Китай) скоро начнет работать в 
Украине. Хорошее начало для работы китайских компаний в Украине положено, есть надежда на совместную реализацию масштабных проектов, которые дадут Украине новое качество, а Китаю - новые успешные бизнес-проекты.

\section{8. Общая оценка результатов исследований}

В работе продемонстрирована динамичность рыночных позиций портов Китая на конкурентной карте мирового портового рынка, определены факторы развития конкурентных позиций и ключевые глобальные тренды. Их учет и использование при повышении эффективности работы морских портов Украины должны привести к повышению качества услуг, росту вклада в ВВП и усилению конкурентных позиций морских портов Украины. Реализация стратегии развития на научной основе, с учетом инвестиций и опыта Китая, а также других стран, позволит морским портам Украины:

- увеличить объемы грузопереработки;

- расширить номенклатуру перегружаемых грузов;

- использовать выгодное географическое положение страны на пересечении транспортных коридоров для повышения конкурентоспособности;

- развивать рыночные позиции;

- проводить исследования, особенно в сфере повышения энергоэффективности и ресурсосбережения;

- найти источники инвестиций для сохранения и обновления инфраструктурных и производственных мощностей.

Негативное влияние экономической ситуации в регионе снижает темпы развития большинства предприятий Украины, в том числе и морских портов. Ограничение возможностей накопления резервов собственных средств на инвестиционные проекты существенно тормозит дальнейшее развитие отрасли. К другим недостаткам следует отнести то, что формирование новой бизнесмодели портов Украины займет довольно продолжительное время, потребует привлечения финансовых ресурсов, современных технологий. Для снижения влияния указанных недостатков следует учесть опыт мировой экспансии портов и транснациональных компаний Китая. Повышение конкурентоспособности морских портов Украины позволит улучшить их финансовые показатели, развивать связанные отрасли, другие виды транспорта. В данных условиях заслуживает внимания специализация морских портов и отдельных причалов на конкретных перспективных видах грузов по примеру портов Китая, с сохранением возможности унификации под другие грузы.

В дальнейших исследованиях закономерностей и особенностей развития морских портов следует особое внимание уделять механизмам регулирования и стимулирования инвестиционной и управленческой деятельности отдельных стейкхолдеров, а также вопросу ценообразования услуг. Преимущества и недостатки повышения эффективности работы морских портов в других странах, особенно таких крупных, как Китай, также должны изучаться для внедрения новейших стратегических решений в морских портах Украины.

Качественные стратегии развития морских портов позволяют минимизировать кратко- и среднесрочные потери и реализовать потенциал в долгосрочной перспективе. К ключевым угрозам повышения эффективности работы морских портов Украины следует отнести недостаточные объемы привлечения капитала, невозможность приобретения современных технологий, ошибки в определении приоритетов как результат слабого аналитического обеспечения принятия решений, утрату кадрами высокого уровня компетенций. 
Неэффективность межсистемных и межотраслевых связей портовой отрасли могут иметь негативное влияние как на сами порты, так и на экономику страны, качество социально-экономического развития, что очевидно из опыта Китая. Геополитические факторы, разрыв налаженных экономических связей также могут негативно влиять на развитие морских портов Украины.

\section{Выводы}

1. Систематизированы основные факторы, которые обуславливают необходимость пересмотра традиционной модели развития морских портов с целью повышения эффективности:

- ресурсные - диверсификация источников ресурсов, в т. ч. средне- и долгосрочных инвестиций, эффективное управление ими;

- научно-образовательные - обеспечение высококвалифицированными кадрами, новыми знаниями, формирование конкурентных моделей и преимуществ;

- технологические - моральное и физическое устаревание инфраструктуры, привлечение новых технологий, в т. ч. иностранных;

- экологические - повышение приоритетов устойчивого развития с учетом влияния на окружающую среду;

- рыночные - конкуренция со стороны иностранных морских портов, видов транспорта и транспортных коридоров;

- экономические и социальные - стратегическая необходимость обеспечения национальной экономической безопасности, занятости населения и развития взаимосвязанных отраслей.

2. Обобщение опыта Китая позволило определить, что развитие инфраструктуры мирового рынка происходит в условиях возрастания участия частного сектора, что приводит к усилению его контроля над такими стратегически важными узлами, как морские порты. Развитие государственно-частного партнерства может оформляться в виде самых разных моделей, ключевыми измерениями которых являются форма собственности на землю, регулирование и операционная деятельность. При этом развитие морских портов, специализацией которых является обеспечение сырьевых товаропотоков, становится второстепенным, хотя и имеются различия между странами по мере участия в логистических цепочках.

3. Построение конкурентной карты мирового портового рынка позволило идентифицировать его лидеров (Китай) и позиции Украины. Она демонстрирует динамичность позиций морских стран на мировом портовом рынке. Первая десятка крупнейших стран в мировой торговле, которая контролирует порядка $50 \%$ его объема, эффективно представлена на мировом портовом рынке (табл. 3-4). Она состоит преимущественно из развитых стран и стран, в которые транснациональные корпорации перемещают производства (Китай, Мексика), приоритеты стратегий развития которых включают импорт сырьевых товаров и экспорт товаров с высокой добавленной стоимостью. Украины и ее морских портов характерны слабые и аутсайдерские позиции на мировой карте, что обусловлено качеством и характером реализации стратегии развития.

4. Результаты проведенного исследования позволили предложить ключевые направления управления конкурентоспособностью украинских морских портов на основе опыта Китая. Стратегия развития каждого морского порта и отрасли в целом должна включать взвешенное решение таких ключевых компонентов: 
- привлечение инвестиций и управление рисками в условиях обеспечения конкурентоспособности и национальной безопасности;

- обеспечение мониторинга конкурентных позиций на мировом рынке;

- развитие межсистемных связей, особенно в контексте качественной продуктивности научно-образовательных и технологических факторов.

5. Определено, что наиболее для развитых стран, в т. ч. и для Китая, характерно формирование цепочек "наука - технологии - образование" и "производство - транспортно-логистическая инфраструктура", которые вносят наибольший вклад в конкурентоспособность страны, ее компаний и морских портов. Крепким позициям развитых стран на мировом рынке предшествовала активизация научных и прикладных исследований различных аспектов конкурентоспособности портов (табл. 4), на основании которых развивались технологии, появилась концепция компетенций, совершенствовались подходы к менеджменту. Для развитых стран характерна приоритезация экологических аспектов, которые могут быть следующим компонентом этих цепочек. Украине еще только предстоит оценить и перенять этот положительный опыт.

\section{ЛИТЕРАТУРА}

Гапочка А. А. Международные морские порты-хабы как фактор развития региона Балтийского моря. Санкт-Петербург, 2017. - URL: https:/disser. spbu.ru/files/disser2/disser/1WXZVyzNrc.pdf (дата обращения: 1.08.2018).

Зинченко С. Г. Контроллинг эксплуатации и ремонта объектов транспортно-технологической системы морского порта в условиях дерегуляции перевозки грузов и наличия суброгацийного оборудования. Мариуполь: ООО “ППНС”, 2017.

Ільнищький Д. О., Зінченко С. Г. Пошук ідеальної моделі транспортно-технологічної системи порту: компетентнісний вимір // Вісник Одеського національного університету: серія "Економіка", 2017. Т. 22. Вип. 5 (58). C. 87-97.

Клепиков В. П. Логистическая инфраструктура Азовского морского региона в новых условиях // Логистика и управление цепями поставок, 2016. № 1. С. 69-79.

Кузнецов А. Л. Генезис моделей развития портов в современной транспортной науке // Вестник государственного университета морского и речного флота им. адмирала Макарова, 2015. № 2 (30). С. 141-153.

Муравский $A$. Военно-торговая логистика: Китай увеличил инвестиции в иностранные порты. - URL: https://ports.com.ua/articles/voenno-torgovaya-logistika-kitay-uvelichil-investitsii-v-inostrannye-porty (дата обращения: 6.08.2018).

Наукометрическая база ScienceDirect. - Режим доступа: www.sciencedirect.com (дата обращения:18.03.2018).

Носков А. Портовая инфраструктура стран Северной Африки и ее влияние на интеграцию в Средиземноморье // Азия и Африка сегодня, 2017. № 5. C. $21-25$.

Официальный сайт государственного предприятия "Администрация морских портов Украины” / Раздел “Показатели работы”. - Режим доступа: http://uspa.gov.ua/ru/pokazateli-raboty

Сайт компании "Центр финансово-транспортных стратегий" / Китайские компании за последний год объявили о 20 млрд долл. инвестиций в зарубежные порты / Раздел “Новости”, 9.10.2017. - Режим доступа: https://cfts.org. 
ua/news/2017/10/09/kitayskie kompanii za posledniy god obyyavili o $20 \mathrm{mlrd}$ dollarov_investitsiy_v_zarubezhnye_porty_43348 (дата обращения: $\overline{6} . \overline{08} .2018$ ).

Финансовая отчетность. Администрация морских портов Украины. - URL: http://www.uspa.gov.ua/ru/finansovaya-otchetnost (дата обращения: 29.04.2018).

Ambrosino D. Location of mid-range dry ports in multimodal logistic networks // Procedia - Social and Behavioral Sciences: AIRO Winter 2013/2014. № 108. Pp. 118-128.

An in-house university with its sights set on the future // CMA CGM Magazine, Winter 2017/2018. - URL: https:/www.cma-cgm.com/media/magazine-article/26/ the-experts-cma-cgm-academy-an-in-house-university-with-its-sights-set-on-the-future (дата обращения: 30.04.2018).

Awad-Núñeza S. Application of a model based on the use of DELPHI methodology and Multicriteria Analysis for the assessment of the quality of the Spanish Dry Ports location // Procedia - Social and Behavioral Sciences: XVIII Congreso Panamericano de Ingeniería de Tránsito, Transporte y Logística, 2014. № 162. Pp. 42-50.

Bagočius V. Multi-Criteria Selection of a Deep-Water Port in Klaipeda // Procedia Engineering, 2013. № 57. Pp. 144-148.

Chan $S$. The Belt and Road Initiative: Implications for China and East Asian Economies // The Copenhagen Journal of Asian Studies, 2018, № 35(2). C. 52-78.

Chen S-L. Malaysian Container Seaport-Hinterland Connectivity: Status, Challenges and Strategies // The Asian Journal of Shipping and Logistics, 2016. № 32 (3). Pp. 127-137.

Chen Yougang, Matzinger Stefan, Woetzel Jonathan. Chinese infrastructure: The big picture. McKinsey Quarterly. June 2013. - URL: https://www.mckinsey. com/featured-insights/winning-in-emerging-markets/chinese-infrastructure-thebig-picture (дата обращения: 30.07.2018).

Comprehensive Annual Financial Report June 30, 2017 and 2016. Port of Los Angeles. - URL: https://www.portoflosangeles.org/Publications/ Annual_Financial_Report_FY_2016-17.pdf (дата обращения: 30.04.2018).

Container shipping: The next 50 years // Travel, Transport \& Logistics, October 2017. - URL: https://www.safety4sea.com/ wp-content/uploads/2017/10/McKinseyContainer-shipping-The-next-50-years-2017_10.pdf (дата обращения: 30.04.2018).

Dong-Jin Kim. A comparison of efficiency with productivity criteria for European container ports // The Asian journal of shipping and logistics, August 2012. Volume 28, Number 2. Pp. 183-202.

Esmer S. A simulation for optimum terminal truck number in a Turkish port based on lean and green concept / Soner Esmer, Ismail Bilge Cetin, Okan Tuna // The Asian journal of shipping and logistics, December 2010. Volume 26, Number 2. Pp. 277-296.

Exports of goods and services. Worldbank Statistics database. World Bank Group. - URL: https://data.worldbank.org/indicator/NE.EXP.GNFS.ZS (дата обращения: 27.04.2018).

Galvao C. B. Public-Private Interests and Conflicts in Ports: A Content Analysis Approach // The Asian Journal of Shipping and Logistics, 2016. № 32 (1). Pp. 013-022.

Gianfranco F. Port Cooperation Policies in the Mediterranean Basin: an Experimental Approach using Cluster Analysis // Transportation Research Procedia, 2014. № 3. Pp. 700-709. 
Gogas M. Assessing the performance of intermodal city logistics terminals in Thessaloniki // Transportation Research Procedia: $3^{\text {rd }}$ Conference on Sustainable Urban Mobility, 26-27 May 2016, Volos, Greece. 2017. № 24. Pp. 17-24.

Hamzah S. Private involvement in sustainable management of Indonesian port: Need and strategy with PPP scheme // Procedia Environmental Sciences: $4^{\text {th }}$ International Conference on Sustainable Future for Human Security, 2014. № 20. Pp.187-196.

Hanaoka S. Promoting intermodal freight transport through the development of dry ports in Asia: An environmental perspective // IATSS Research, 2011. № 35. Pp. 16-23.

Jeevan J. Preparation of dry ports for a competitive environment in the container seaport system: A process benchmarking approach // International Journal of e-Navigation and Maritime Economy, 2017. № 7. Pp. 019-033.

Jeon J. W. SNA Approach for Analyzing the Research Trend of International Port Competition // The Asian Journal of Shipping and Logistics, 2016. № 32 (3). Pp. 165-172.

Lagoudis I. Port Investment Strategies under Uncertainty: The Case of a Southeast Asian Multipurpose Port // The Asian Journal of Shipping and Logistics, December 2014. Volume 30, Number 3. Pp. 299-319.

Li J. Cooperation performance evaluation between seaport and dry port; case of Qingdao port and Xi'an port // International Journal of e-Navigation and Maritime Economy, 2014. № 1. Pp. 99-109.

Libardo A., Parolin A. Multicriteria analysis evaluating Venice port development // Procedia - Social and Behavioral Sciences, 2012. № 48. Pp. 2545-2554.

Merchandise: Total trade and share, annual. UNCTAD. - URL: http://unctadstat.unctad.org/wds/TableViewer/tableView.aspx?ReportId=92 (дата обращения: 26.04.2018).

Notteboom T. Port governance in China since 2004: Institutional layering and the growing impact of broader policies // Research in Transportation Business \& Management, 2017. № 22. Pp. 184-200.

Olba $X$. B. Simulating the port wet infrastructure: review and assessment// Transportation Research Procedia: $18^{\text {th }}$ Euro Working Group on Transportation, 2015. № 10. Pp. 683-693.

Ports strategy and logistics challenges: What are the levers for long term vitality? - TDIE Research Council / by Antoine Frémont, Claude Gressier and Pierre Van Cornewal. - URL: http://tdie.eu/wp-content/uploads/2017/01/Ports-strategy-andlogistics-challenges-TDIE-report-Oct.-2016.pdf. (дата обращения: 25.04.2018).

Readiness for the Future of Production Report 2018 (Martin C., Aurik J. etc.). World Economic Forum, 2018. - URL: http://www3.weforum.org/ docs/FOP Readiness_Report_2018.pdf (дата обращения: 28.04.2018).

Review of Maritime Transport 2017 (Jan Hoffmann etc.) UNCTAD. October 2017. - URL: http://unctad.org/rmt (дата обращения: 28.04.2018).

Rudjanakanoknad J. Evaluation of International Ports in Thailand through Trade Facilitation Indicies from Freight Forwarders // Procedia - Social and Behavioral Sciences. EWGT 2013-16 ${ }^{\text {th }}$ Meeting of EURO Working Group on Transportaton, 2014. № 111. Pp. 1073-1082.

Sayareh J. A Hybrid Decision-Making Model for Selecting Container Seaport in the Persian Gulf // The Asian journal of shipping and logistics, April 2014. Volume 30, Number 1. Pp. 75-95. 
Seo J. The Role of Port Size and Incentives in the Choice of Location by Port Users: A Game-Theoretic Approach // The Asian Journal of Shipping and Logistics, June 2010. Volume 26, Number 1. Pp. 049-066.

Song D.-W. Port governance in Korea: Revisited // Research in Transportation Business \& Management, 2017. № 22. Pp. 27-37.

Sugawara J. Port and hinterland network: a case study of the Crescent Corridor intermodal freight program in the US // Transportation Research Procedia, 2017. № 25. Pp. 916-927.

Sutomo H. Assessment Model of the Port Effectiveness and Efficiency (Case Study: Western Indonesia Region) // Procedia - Social and Behavioral Sciences: $8^{\text {th }}$ International Conference on Traffic and Transportation Studies Changsha, China, August 1-3. 2012. № 43. Pp. 24-32.

The Competitiveness of Global Port-Cities: Synthesis Report / Edited by Olaf Merk. OECD. - URL: www.oecd.org/regional/portcities. (дата обращения: 28.04.2018).

The Port-city Universities League Secretariat. Yokohama National University. URL: http://www.pul.ynu.ac.jp (дата обращения: 30.04.2018).

Thomson H. Natural gas as a marine fuel // Energy Policy, 2015. № 87. Pp. 153167.

Trade and tariff data. WTO Statistics database. WTO. - URL: https://www. wto.org/english/res_e/statis_e/statis_e.htm (дата обращения: 29.04.2018).

Urbanyi-Popiołek I. Container terminals and port city interface - a study of Gdynia and Gdańsk ports // Transportation Research Procedia: $2^{\text {nd }}$ International Conference "Green Cities - Green Logistics for Greener Cities", Szczecin, Poland, 2016. № 16. Pp. 517-526.

Wiśnicki $B$. Conditions for developing a port city transport infrastructure illustrated with the example of Szczecin agglomeration// Transportation Research Procedia: $2^{\text {nd }}$ International Conference "Green Cities - Green Logistics for Greener Cities”, 2-3 March 2016. Szczecin, Poland, 2016. № 16. Pp. 566-575.

Woo-chul A. Study on the Securement of the Competitiveness of Gyeong-In Port // The Asian journal of shipping and logistics, August 2014. Volume 30, Number 2. Pp. 243-264.

$X u$ M. Port Governance in China: Devolution and Effects Analysis // Procedia Social and Behavioral Sciences, 2012. № 43. Pp. 14-23.

\section{REFERENCES}

Gapochka, A. (2017), Mezhdunarodnie morskie porty-haby kak faktor razvytyia regoina Baltiiskogo moria, St.-Peterburg. - URL: https://disser.spbu.ru/files/disser2/disser/1WXZVyzNrc.pdf (Accessed on: 1.08.2018).

Zynchenko S. (2017), Kontrolling ekspluatacii i remonta obektov transportnotekhnolohichnoi systemy morskogo porta v uslovijah deregulasii perevozki gruzov $i$ nalichija subrogazijnogo oborudovanija. Mariupol, $159 \mathrm{p}$.

Ilnytskyy D. O., Zinchenko S. H. (2017), Poshuk idealnoi modeli transportnotekhnolohichnoi systemy portu: kompetentnisnyi vymir, Visnyk Odeskoho natsionalnoho universytetu: seriia "Ekonomika", v. 22, n. 5 (58), pp. 87-97.

Klepykov V. (2016), Lohystycheskaia ynfrastruktura Azovskoho morskoho rehyona $\mathrm{v}$ novykh uslovyiakh, Lohystyka y upravlenye tsepiamy postavok, № 1, pp. 69-79. 
Kuznetsov A., Halyn A. (2015), Henezys modelei razvytyia portov v sovremennoi transportnoi nauke, Vestnyk hosudarstvennoho unyversyteta morskoho y rechnoho flota im. admyrala Makarova, № 2 (30), pp. 141-153.

Muravskyy A., Voenno-torgovaia lohystika: Kitay uvelichil investitsyy v inostrannye porty - URL: https://ports.com.ua/articles/voenno-torgovaya-logistika-kitay-uvelichil-investitsii-v-inostrannye-porty (Accessed on: 6.08.2018).

ScienceDirect. Database. - URL: www.sciencedirect.com (Accessed on: 18.03.2018).

Noskov A. (2017), Portovaia infrastruktura stran Severnoi Afryky i ee vlyianye na intehratsyiu v Sredyzemnomore, Azyia y Afryka sehodnia, № 5, pp. 21-25.

Official site, Admynystratsyia Morskykh Portov Ukrayny. - URL: http://uspa. gov.ua/ru/pokazateli-raboty

Site, Tsentr finansovo-transportnyh strategyy, Kitayskie kompanyi za poslednyy god obiavili o $20 \mathrm{mlrd}$. dol. investitsyy v zarubezhnye porty, 9.10.2017. - URL: https://cfts.org.ua/news/2017/10/09/kitayskie_kompanii_za_posledniy_god_obyyavili_o_20_mlrd_dollarov_investitsiy_v_zarubezhnye_porty_43348 (Accessed on: 6.08.2018).

Fynansovaia otchetnost, Admynystratsyia Morskykh Portov Ukrayny. - URL: http://www.uspa.gov.ua/ru/finansovaya-otchetnost (Accessed on: 21.04.2018).

Ambrosino D., Sciomachen A. (2014), Location of mid-range dry ports in multimodal logistic networks. Procedia-Social and Behavioral Sciences: AIRO, № 108, pp. 118-128.

An in-house university with its sights set on the future, CMA CGM Magazine, Winter 2017/2018. - URL: https://www.cma-cgm.com/media/magazine-article/26/ the-experts-cma-cgm-academy-an-in-house-university-with-its-sights-set-on-thefuture (Accessed on: 30.04.2018).

Awad-Núñeza S., González-Cancelasa I., Camarero-Orive A. (2014), Application of a model based on the use of DELPHI methodology and Multicriteria Analysis for the assessment of the quality of the Spanish Dry Ports location, ProcediaSocial and Behavioral Sciences: XVIII Congreso Panamericano de Ingeniería de Tránsito, Transporte y Logística, № 162, pp. 42-50.

Bagočius V., Zavadskas E. K., Turskis Z. (2013), Multi-Criteria Selection of a Deep-Water Port in Klaipeda, Procedia Engineering, № 57, pp. 144-148.

Chan S. (2018), The Belt and Road Initiative: Implications for China and East Asian Economies, The Copenhagen Journal of Asian Studies, № 35(2), pp. 52-78.

Chen S-L., Jeevan J., Cahoon S. (2016), Malaysian Container Seaport-Hinterland Connectivity: Status, Challenges and Strategies, The Asian J. of Shipping and Logistics, № 32 (3), pp. 127-137.

Chen Yougang, Matzinger Stefan, Woetzel Jonathan, Chinese infrastructure: The big picture, McKinsey Quarterly. June 2013. - URL: https://www.mckinsey. com/featured-insights/winning-in-emerging-markets/chinese-infrastructure-thebig-picture (Accessed on: 30.07.2018).

Comprehensive Annual Financial Report (June 30, 2017 and 2016), Port of Los Angeles. - URL: https://www.portoflosangeles.org/Publications/ Annual_Financial_Report_FY_2016-17.pdf(Accessed on: 30.04.2018).

Saxon S., Stone M. (October 2017), Container shipping: The next 50 years. Travel, Transport \& Logistics, 36 p. - URL: https:/www.safety4sea.com/wp-content/uploads/2017/10/McKinsey-Container-shipping-The-next-50-years-2017_10. pdf (Accessed on: 30.04.2018). 
Dong-Jin Kim. (August 2012), A comparison of efficiency with productivity criteria for European container ports, The Asian J. of Shipping and Logistics, № 28 (2), pp. 183-202.

Esmer S., Cetin I. B., Tuna O. (December 2010), A simulation for optimum terminal truck N.in a Turkish port based on lean and green concept, The Asian J. of Shipping and Logistics, V. 26 (2), pp. 277-296.

Exports of goods and services. Worldbank Statistics database, World Bank Group. - URL: https://data.worldbank.org/indicator/NE.EXP.GNFS.ZS (Accessed on: 27.04.2018).

Galvao C., Wang G. W. Y., Mileski J. (2016), Public-Private Interests and Conflicts in Ports: A Content Analysis Approach, The Asian J. of Shipping and Logistics, № 32 (1), pp. 013-022.

Gianfranco F., Claudia P., Patrizia S., Paolo F. (2014), Port Cooperation Policies in the Mediterranean Basin: an Experimental Approach using Cluster Analysis, Transportation Research Procedia, № 3, pp. 700-709.

Gogas M., Adamos G., Nathanail E. (2017), Assessing the performance of intermodal city logistics terminals in Thessaloniki, Transportation Research Procedia: $3^{\text {rd }}$ Conf. on Sustainable Urban Mobility, 26-27 May 2016, Volos, Greece, № 24, pp. 17-24.

Hamzah S., Adisasmita S., Harianto T., Pallu M. S. (2014), Private involvement in sustainable management of Indonesian port: Need and strategy with PPP scheme, Procedia Environmental Sciences: $4^{\text {th }}$ Intl. Conf. on Sustainable Future for Human Security, № 20, pp. 187-196.

Hanaoka S., Regmi M. (2011), Promoting intermodal freight transport through the development of dry ports in Asia: An environmental perspective, IATSS Research, № 35, pp. 16-23.

Jeevan J., Salleh H., Loke K., Saharuddin A. (2017), Preparation of dry ports for a competitive environment in the container seaport system: A process benchmarking approach, Intl. J. of e-Navigation and Maritime Economy, № 7, pp. 019-033.

Jeon J. W., Wang Y., Yeo G. T. (2016), SNA Approach for Analyzing the Research Trend of Intl. Port Competition, The Asian J. of Shipping and Logistics, № 32 (3), pp. 165-172.

Lagoudis I., Rice J., Salminen J. (2014), Port Investment Strategies under Uncertainty: The Case of a Southeast Asian Multipurpose Port, The Asian J. of Shipping and Logistics, Vol. 30, № 3, pp. 299-319.

Li J., Jiang B. (2014), Cooperation performance evaluation between seaport and dry port; case of Qingdao port and Xi'an port. Intl. J. of e-Navigation and Maritime Economy, № 1, pp. 99-109.

Libardo A., Paroli A. (2012), Multicriteria analysis evaluating Venice port development, Procedia - Social and Behavioral Sciences, № 48, pp. 2545-2554.

Merchandise: Total trade and share, annual, UNCTAD. - URL: http://unctadstat.unctad.org/wds/TableViewer/tableView.aspx?ReportId=92 (Accessed on: 26.04.2018).

Notteboom T., Yang Z. (2017), Port governance in China since 2004: Institutional layering and the growing impact of broader policies, Research in Transportation Business \& Management, № 22, pp. 184-200.

Olba X. B., Daamen W., Vellinga T., Hoogendoorn S. P. (2015), Simulating the port wet infrastructure: review and assessment, Transportation Research Procedia: $18^{\text {th }}$ Euro Working Group on Transportation, № 10, pp. 683-693. 
Frémont A., Gressier C., Van Cornewal P. (2017), Ports strategy and logistics challenges: What are the levers for long term vitality? TDIE Research Council, 56 p. - URL: http://tdie.eu/wp-content/uploads/2017/01/Ports-strategy-and-logistics-challenges-TDIE-report-Oct.-2016.pdf (Accessed on: 25.04.2018).

Martin C., Aurik J. etc. (Eds.). (2018), Readiness for the Future of Production Report World Economic Forum, 266 p. - URL: http://www3.weforum.org/docs/ FOP_Readiness_Report_2018.pdf(Accessed on: 28.04.2018).

Hoffmann, J., etc. (October 2017) Review of Maritime Transport 2017. UNCTAD, 130. - URL: http://unctad.org/rmt (Accessed on: 28.04.2018).

Rudjanakanoknad J., Suksirivoraboo, W., Sumalee S. (2014), Evaluation of Intl. Ports in thailand through Trade Facilitation Indicies from Freight Forwarders, Procedia - Social and Behavioral Sciences. EWGT 2013-16 $6^{\text {th }}$ Meeting of EURO Working Group on Transportaton, № 111, pp. 1073-1082.

Sayareh J., Alizmini H. (April 2014), A Hybrid Decision - Making Model for Selecting Container Seaport in the Persian Gulf, The Asian J. of Shipping and Logistics, № 30 (1), pp. 75-95.

Seo J., Ha Y.-S. (2010), The Role of Port Size and Incentives in the Choice of Location by Port Users: A Game-Theoretic Approach, The Asian J. of Shipping and Logistics, № 26 (1), pp. 049-066.

Song D.-W., Lee S.-W. (2017), Port governance in Korea: Revisited, Research in Transportation Business \& Management, № 22, pp. 27-37.

Sugawara J. (2017), Port and hinterland network: a case study of the Crescent Corridor intermodal freight program in the US, Transportation Research Procedia, № 25, pp. 916-927.

Sutomo H., Soemardjito J. (2012), Assessment Model of the Port Effectiveness and Efficiency (Case Study: Western Indonesia Region), Procedia - Social and Behavioral Sciences: $8^{\text {th }}$ Intl. Conf. on Traffic and Transportation Studies Changsha, China, № 43, pp. 24-32.

The Competitiveness of Global Port-Cities: Synthesis Report. Ed. by Olaf Merk, OECD. - URL: www.oecd.org/regional/portcities (Accessed on: 28.04.2018).

The Port-city Universities League Secretariat, Yokohama National University. URL: http://www.pul.ynu.ac.jp (Accessed on: 30.04.2018).

Thomson H., Corbett J., Winebrake J. (2015), Natural gas as a marine fuel, Energy Policy, № 87, pp. 153-167.

Trade and tariff data, WTO Statistics database, WTO. - URL: https://www.wto. org/english/res_e/statis_e/statis_e.htm (Accessed on: 29.04.2018).

Urbanyi-Popiołek I., Klopott M. (2016), Container terminals and port city interface-a study of Gdynia and Gdańsk ports, Transportation Research Procedia: $2^{\text {nd }}$ Intl. Conf. "Green Cities - Green Logistics for Greener Cities”, № 16, pp. 517526.

Wiśnicki B., Kujawski A. (2016), Conditions for developing a port city transport infrastructure illustrated with the example of Szczecin agglomeration, Transportation Research Procedia: 2nd Intl. Conf. "Green Cities - Green Logistics for Greener Cities”, 2-3 March 2016, Szczecin, Poland, № 16, pp. 566-575.

Woo-Chul A., Lee C.-H., Han J.-K. (August 2014), Study on the Securement of the Competitiveness of Gyeong-In Port, The Asian J. of Shipping and Logistics, № 30 (2), pp. 243-264.

Xu M., Chin A. T. H. (2012), Port Governance in China: Devolution and Effects Analysis, Procedia - Social and Behavioral Sciences, № 43, pp. 14-23. 


\section{ПОРТОВА ЕКСПАНСІЯ КИТАЮ - УРОКИ ДЛЯ УКРАЇНИ}

\section{Д. О. Ільницький, С. Г. Зінченко}

Об'єктом дослідження є розвиток морських портів за умов загострення глобальної конкуренції, експансії, реалізації конкурентами агресивних політик та стратегій. Термінальний бізнес завжди, а особливо сьогодні, пропонує більш швидке і гарантоване повернення коштів, більші прибутки на вкладений капітал. Нині Китай володіє портовими терміналами в 34 країнах і ще у 8 країнах планує придбати портові термінали в найближчі 2-3 роки. Так Китай крокує до статусу провідної морської держави, як Англія в XIX сторіччі.

У ході дослідження вивчалися наукові та аналітичні праці, стратегії розвитку морських портів Китаю та інших країн. Використовувалися методика побудови конкурентних карт глобального портового ринку, систематизація чинників та узагальнення сучасних методик дослідження закономірностей та особливостей розвитку морських портів.

Аналіз конкурентної карти виявив значні асиметрії в динаміці та розмірах ринкових часток країн на світовому портовому ринку, що є результатом реалізації унікальних національних, регіональних та місцевих стратегій. Ключовим рушієм їхнього розвитку визначено активне використання за прикладом Китаю державно-приватного партнерства, науково-освітніх і технологічних чинників.

Ключові слова: транспортна інфраструктура, світовий портовий ринок, конкурентна карта, економічний ефект, експансія, інвестиції

\section{ПОРТОВАЯ ЭКСПАНСИЯ КИТАЯ - УРОКИ ДЛЯ УКРАИНЫ}

\section{Д. А. Ильниикий, С. Г. Зинченко}

Объектом исследования является развитие морских портов в условиях интенсификации глобальной конкуренции, экспансии, реализации конкурентами агрессивных политик и стратегий. Терминальный бизнес всегда, тем более сейчас, предлагает более быстрый и гарантированный возврат средств, большую прибыль на вложенный капитал. В настоящее время Китай владеет портовыми терминалами в 34 странах и еще в 8 странах планирует приобрести портовые терминалы в ближайшие 2-3 года. Таким образом Китай собирается стать ведущей морской державой, как Англия в XIX веке.

В ходе исследования изучались научные и аналитические труды, стратегии развития морских портов Китая и других стран. Использовались методика построения конкурентных карт глобального портового рынка, систематизация факторов и обобщение современных методик исследования закономерностей и особенностей развития морских портов.

Анализ конкурентной карты выявил значительные асимметрии в динамике и размерах рыночных долей стран на мировом портовом рынке, что является результатом реализации уникальных национальных, региональных и местных стратегий. Ключевым двигателем их развития определено активное использование по примеру Китая государственно-частного партнерства, научно-образовательных и технологических факторов.

Ключевые слова: транспортная инфраструктура, мировой портовый рынок, конкурентная карта, экономический эффект, экспансия, инвестиции

Стаття надійшла до редакиіï 12.04.2018 